\title{
Enhanced Muscular Dystrophy from Loss of Dysferlin Is Accompanied by Impaired Annexin A6 Translocation after Sarcolemmal Disruption
}

\author{
Alexis R. Demonbreun, * Madison V. Allen, ${ }^{*}$ James L. Warner, ${ }^{*}$ David Y. Barefield, * Swathi Krishnan, ${ }^{\dagger}$ Kaitlin E. Swanson, ${ }^{\dagger}$
} Judy U. Earley, * and Elizabeth M. McNally*

From the Center for Genetic Medicine, ${ }^{*}$ Northwestern University, Chicago; and the Departments of Medicine ${ }^{\dagger}$ and Pathology, ${ }^{\ddagger}$ The University of Chicago, Chicago, Illinois

Accepted for publication

February 11, 2016.

Address correspondence to Alexis R. Demonbreun, Ph.D., Northwestern University, 303

E. Superior Lurie \#7-109, Chicago, IL 60611. E-mail: alexis. demonbreun@northwestern. edu.

\begin{abstract}
Dysferlin is a membrane-associated protein implicated in membrane resealing; loss of dysferlin leads to muscular dystrophy. We examined the same loss-of-function Dysf mutation in two different mouse strains, 129T2/SvEmsJ $\left(D y s f^{129}\right)$ and C57BL/6J $\left(D y s f^{B 6}\right)$. Although there are many genetic differences between these two strains, we focused on polymorphisms in Anxa6 because these variants were previously associated with modifying a pathologically distinct form of muscular dystrophy and increased the production of a truncated annexin A6 protein. Dysferlin deficiency in the $\mathrm{C} 57 \mathrm{BL} / 6 \mathrm{~J}$ background was associated with increased Evan's Blue dye uptake into muscle and increased serum creatine kinase compared to the 129T2/SvEmsJ background. In the C57BL/6J background, dysferlin loss was associated with enhanced pathologic severity, characterized by decreased mean fiber cross-sectional area, increased internalized nuclei, and increased fibrosis, compared to that in Dysf $f^{129}$ mice. Macrophage infiltrate was also increased in $D y s f^{B 6}$ muscle. High-resolution imaging of live myofibers demonstrated that fibers from $D y s f^{B 6}$ mice displayed reduced translocation of full-length annexin $A 6$ to the site of laser-induced sarcolemmal disruption compared to $D y s f^{129}$ myofibers, and impaired translocation of annexin A6 associated with impaired resealing of the sarcolemma. These results provide one mechanism by which the $\mathrm{C} 57 \mathrm{BL} / 6 \mathrm{~J}$ background intensifies dysferlinopathy, giving rise to a more severe form of muscular dystrophy in the $D y s f^{B 6}$ mouse model through increased membrane leak and inflammation. (Am J Pathol 2016, 186: 1610-1622; http://dx.doi.org/10.1016/j.ajpath.2016.02.005)
\end{abstract}

Muscular dystrophies are a class of genetic myopathies characterized by progressive deterioration of muscle. Lossof-function mutations in the gene encoding dysferlin (known as DYSF or FERIL1) produce a range of muscle diseases in humans. ${ }^{1-3}$ Dysferlin belongs to a larger family of proteins, the ferlin family; family members are defined as having multiple $\mathrm{C} 2$ domains similar to those found in the classic $\mathrm{Ca}^{2+}$-sensitive phospholipid binding protein synaptotagmin. C2 domains bind negatively charged phospholipids in the presence of $\mathrm{Ca}^{2+}$. Through its carboxyterminal transmembrane domain, dysferlin localizes to the plasma membrane and to the transverse tubule, a membranous network that coordinates $\mathrm{Ca}^{2+}$ handling and contraction in muscle. ${ }^{4-6}$ The most well-characterized role of dysferlin is as a mediator of skeletal muscle membrane repair. Bansal et al $^{7}$ utilized a laser to ablate the sarcolemma and image repair in live myofibers. Dysf-null fibers resealed sarcolemmal disruption more slowly than did normal fibers, as shown by increased extracellular dye influx. ${ }^{7}$ This defect in membrane repair and other roles of dysferlin correlate with the development of muscular dystrophy. ${ }^{8}$

Loss of dysferlin in humans and mice is characterized by significantly elevated serum creatine kinase (CK) levels, a marker of muscle injury and disease, and progressive

Supported by NIH grants NS047726, NS072027, and AR052646 (all to E.M.M.). Multiphoton microscopy was performed at the Northwestern University Center for Advanced Microscopy on a Nikon A1R multiphoton microscope acquired through the support of NIH grant 1S10OD010398-01.

Disclosures: None declared. 
muscle weakness. Elevated levels of serum CK are evident before the onset of muscle weakness. Additionally, muscle biopsy samples show increased numbers of inflammatory cells, including macrophages, within the muscle. ${ }^{3,8-10}$ The inflammatory infiltrate seen in the muscle biopsy samples in dysferlin-linked muscle disease may result in a misdiagnosis as polymyositis, an autoimmune myopathy. ${ }^{11,12}$ It has been reported that the same loss-of-function mutation in the $D Y S F$ gene can result in both mild and severe forms of disease, indicating that other factors modify the disease outcome. ${ }^{13}$ Additionally, the same genetic lesion, R1905X, has been reported to result in the full range of dysferlinassociated phenotypes, including limb-girdle muscular dystrophy 2B, Miyoshi myopathy, and distal anterior compartment myopathy. ${ }^{14}$ Anxa6, which encodes annexin A6, was identified as a genetic modifier of limb-girdle muscular dystrophy $2 \mathrm{C}$ in mice. ${ }^{15}$ In zebrafish, a genetic interaction was identified between mutations in the genes encoding dysferlin and annexin A6. ${ }^{15,16}$ Anxa6 was found to modify muscular dystrophy in mice lacking the dystrophin-associated protein $\gamma$-sarcoglycan, and a loss of $\gamma$-sarcoglycan produces muscular dystrophy by causing sarcolemmal instability. ${ }^{17}$ We now queried whether the genetic background modifies dysferlinopathy, because dysferlin produces muscle disease by disrupting membrane trafficking and repair. ${ }^{18}$

Annexins are membrane-associated proteins that typically contain four annexin repeats, domains known to bind $\mathrm{Ca}^{2+}$ and the actin cytoskeleton. ${ }^{19}$ Transient and localized $\mathrm{Ca}^{2+}$ elevation triggers annexin trafficking and membrane binding. ${ }^{20}$ Annexins $\mathrm{A} 1$ and $\mathrm{A} 2$ bind dysferlin in vitro and may be involved in sarcolemmal membrane repair in cultured myotubes and in zebrafish muscle. ${ }^{16,21}$ Annexins A1 and A2 are cleaved into protein byproducts and are found extracellularly. ${ }^{22,23}$ An anti-inflammatory role of annexins A1 and $\mathrm{A} 2$ has been postulated, as mice lacking annexin A1 have a greatly enhanced response to inflammatory stimuli. ${ }^{24}$

Annexin A6 is an atypical annexin with eight annexin repeats, two regions composed of four repeats connected by a middle hinge. Evolutionarily, annexin A6 has been speculated to have arisen from a gene-duplication event combining annexins A5 and A10. ${ }^{25,26}$ The four amino-terminal annexin domains are highly homologous to annexins A1 and A2. ${ }^{20}$ Annexin A6 may be involved in muscle membrane repair in zebrafish and mouse skeletal muscle. ${ }^{15,16}$ In both zebrafish and mouse sarcolemmal disruption, annexin A6 was observed to translocate quickly to the site of sarcolemmal disruption. ${ }^{15,16}$ In vitro studies have proposed annexin A6 as capable of membrane binding through both sets of annexin repeat domains, where it facilitates membrane coalescence of two opposing membranes. ${ }^{27}$

To better understand the role that the genetic background plays in dysferlin-related muscle disease, we evaluated mouse models harboring the same Dysf-null mutation backcrossed onto two different murine background strains, C57BL/6J and 129T2/SvEmsJ, generating Dysf $f^{\mathrm{B} 6}$ and $D y s f^{129}$ mouse models, respectively. Dysf $f^{B 6}$ mice have increased serum CK leak and influx of Evans Blue dye (EBD), suggestive of impaired membrane resealing. Consistent with inefficient repair, Dysf ${ }^{\mathrm{B} 6}$ muscle pathology, characterized by increased central nuclei, decreased myofiber size, elevated immune infiltrate, and increased fibrosis, is more severe than Dysf $f^{129}$ muscle pathology. We conducted laser disruption of the sarcolemma in Dysf myofibers from both genetic backgrounds and found delayed membrane repair marked by dye uptake in $D y s f^{\mathrm{B} 6}$ compared to $D y s f^{129}$ muscle, consistent with increased disease severity. Although there are many genetic differences between these strains, the C57BL/6J strain carries the same Anxa6 allele described in the DBA2J background that produces low-level expression of truncated annexin A6. ${ }^{15}$ We now show that the Dysf ${ }^{\mathrm{B} 6}$ strain carries Anxa6 gene polymorphisms and the alternatively spliced Anxa6 transcript seen in the DBA2J background. This alternatively spliced Anxa6 transcript resulted in the expression of a truncated form of annexin A6, A6N32. Upon sarcolemmal disruption, we found impaired translocation of the full-length A6 protein to the site of membrane injury in the C57BL/6J strain compared to those from the 129T2/SvEmsJ background. This cellular defect of impaired annexin A6 translocation provides a molecular explanation for the more severe progression of muscle disease in the $D y s f^{\mathrm{B} 6}$ mice, through its modulation of membrane leak and immune infiltration.

\section{Materials and Methods}

\section{Animals}

Wild-type 129T2/SvEmsJ (WT ${ }^{129}$ ), WT C57BL/6J (WT ${ }^{\mathrm{B} 6}$ ), $D y s f^{129},{ }^{28}$ and $D y s f^{B 629}$ mice were housed in uniform conditions in a single, barrier facility. Congenic mice, $D y s f^{129} ; L t b p 4^{\mathrm{d} / \mathrm{d}}$ and $D y s f^{129} ; L t b p P 4^{\text {ili }}$ mice, were generated by crossing DBA2J mice with $D y s f^{129}$ mice over five generations to generate mice that carried both the Dysf-null and Ltbp4 deletion $\left(L t b p 4^{\mathrm{d} / \mathrm{d}}\right)$ alleles on the 129 background strain. All animals were housed and treated in accordance with the standards set by the Animal Care and Use Committee.

\section{Muscle Analysis}

Muscles from $\mathrm{WT}^{129}, \mathrm{WT}^{\mathrm{B} 6}, D y s f^{129}$, and $D y s f^{\mathrm{B} 6}$ mice were examined at $>52$ weeks of age. The quadriceps muscles were dissected from tendon to tendon $(n \geq 3$ mice). The excised muscle was immediately frozen in liquid nitrogen and stored at $-80^{\circ} \mathrm{C}$. Sections from the center of the muscle were stained with hematoxylin and eosin. The amount of fibers with internal nuclei was calculated as the number of fibers containing internal nuclei/the total number of fibers counted per image, standardized as a percentage ( $n \geq 250$ fibers per animal). Mean fiber size and fiber variation were calculated using the cross-sectional area of individual myofibers ( $n \geq 1208$ fibers per animal; $n \geq 3$ animals per genotype). Statistical analysis was performed with Prism 
software version 6.0h (GraphPad Software, Inc., San Diego, CA) using a two-way analysis of variance test. Dysf $f^{129} ; L t b p 4^{\text {i/i }}$ and $D y s f^{129} ; L t b p 4^{\mathrm{d} / \mathrm{d}}$ muscles were examined using similar methods as described earlier in this paragraph from mice at $\geq 6$ months of age $(n \geq 3)$.

\section{Fibrosis Quantification Analysis}

Quadriceps muscles from $>52$-week-old $\mathrm{WT}^{129}, \mathrm{WT}^{\mathrm{B} 6}$, $D y s f^{129}$, and $D y s f^{B 6}$ mice were sectioned and stained with Picrosirius red (\#24901; Polysciences Inc., Warrington, PA). Representative images of stained muscle sections were taken at $\times 20$ magnification. Using ImageJ plug-in software version $1.50 \mathrm{i}$ (NIH, Bethesda, MD) ${ }^{30}$ the amount of Picrosirius red-stained collagen was quantified from at least three fields per animal ( $n \geq 3$ animals per genotype). Statistical analysis was performed with Prism software (GraphPad) using a twoway analysis of variance test. Muscles from $D y s f^{129} ; L t b p 4^{\mathrm{i} / \mathrm{i}}$ and $D y s f^{129} ; L t b p 4^{\mathrm{d} / \mathrm{d}}$ mice $(n \geq 3)$ were stained with Masson's trichrome and imaged identically $(n \geq 3)$.

\section{EBD Imaging and Quantification}

EBD uptake into muscle was quantified as described previously. ${ }^{31}$ Briefly, EBD (E-2129; Sigma-Aldrich, St. Louis, MO) was dissolved in phosphate-buffered saline at $10 \mathrm{mg} / \mathrm{mL}$. Each animal received an i.p. injection of EBD at $5 \mu \mathrm{L} / \mathrm{g}$ body weight. Approximately 48 hours after injection, tissues were harvested. For quantification, whole tissue was dissected, finely minced, weighed, and incubated at $55^{\circ} \mathrm{C}$ in $1 \mathrm{~mL}$ of formamide for 2 hours, with shaking. Spectrophotometric absorbance was measured at $620 \mathrm{~nm}$. Statistical analysis was performed with Prism software (GraphPad) using an unpaired $t$-test.

\section{Macrophage Visualization}

EBD was injected as described in the previous section. Tissue was harvested and flash-frozen in liquid nitrogen. Muscle was sectioned and stained with F4/80 Alexa Fluor 488 (NB600-404AF488; Novus Biologicals, Littleton, CO) used at a dilution of 1:100. Sections were mounted in Vectashield with DAPI (Vector Laboratories, Burlingame, CA). Images were acquired on an Axio Imager.M2 (Carl Zeiss, Oberkochen, Germany). F4/80 $0^{+}$cells were quantified from at least three fields and four animals per genotype. Statistical analysis was performed with Prism software (GraphPad) using an unpaired $t$-test.

\section{Immunoblot Analysis}

Proteins transferred to polyvinylidene difluoride membranes were immunoblotted with anti-annexin A6 antibody (ab31026; Abcam, Cambridge, UK) used at a dilution of 1:4000. A secondary antibody, goat anti-rabbit conjugated to horseradish peroxidase (Jackson ImmunoResearch
Laboratories, West Grove, PA) was used at 1:5000. Blocking and antibody incubations were performed in StartingBlock T20 Blocking Buffer (Pierce, Rockford, IL). SuperSignal West Pico Chemiluminescent Substrate (Thermo Fisher Scientific, Rochester, NY) and a BioSpectrum Imaging System (UVP, Upland, CA) were used for imaging. As a loading control, MemCode (Thermo Fisher Scientific) was used for reversibly stained, transferred whole muscle lysate. Images were quantified from at least three mice per genotype using ImageJ software (NIH).

\section{RT-PCR and Quantitative PCR Analysis}

RNA was isolated from the abdominal muscles and tibialis anterior muscles of age- and sex-matched $\mathrm{WT}^{129}, \mathrm{WT}^{\mathrm{B} 6}$, $D y s f^{129}$, and $D y s f^{86}$ mice ( $n=3$ per genotype). Tissue was immediately placed in TRIzol (Ambion Diagnostics, Austin, TX) and disrupted using a bead homogenizer, followed by centrifugation for 3 minutes at $12,000 \times g$ at $4^{\circ} \mathrm{C}$. One-fifth volume of chloroform was added, and the tubes were shaken by hand and then incubated for 5 minutes at room temperature before centrifugation for 15 minutes at $12,000 \times g$ at $4^{\circ} \mathrm{C}$. RNA was extracted from the upper phase. RNA extraction was performed using the Aurum Total RNA Mini Kit (Bio-Rad Laboratories, Segrate, Italy) with column DNase digestion, following the manufacturer's guidelines. cDNA was synthesized using qScript cDNA SuperMix (Quanta Biosciences, Gaithersburg, MD) from $1 \mu \mathrm{g}$ of RNA per sample, following the manufacturer's guidelines. Quantitative PCR was performed using iTaq universal SYBR Green supermix (Bio-Rad) in a CFX96 Real-Time PCR Detection System (Bio-Rad). Control reactions were performed with RNA processed using the same method but without RT. PCR was performed for Anxa6 exons 9/10 to exon 15 using the following primers: Anxa6_9.10F, 5'-ACAGCACCTACGACTGGTGTTTGA-3'; Anxa6_15R, 5'-CAATTCCCTTCATGGCTTTCCGCA- ${ }^{\prime}$. These reactions detect the full-length and alternate Anxa6 transcripts with expected product sizes of 515 and $168 \mathrm{bp}$, respectively, for $9.10 \mathrm{~F}$ and $15 \mathrm{R}$. To specifically detect the alternate A6 transcript, the following primer was used: Anxa6_11.15.16R, 5' CAGTTCCAATTCCCTTCATGGCTTTCCGCAAAAT-3', in conjunction with the exon $9 / 10$ forward primers, giving an expected product size for these reactions, $174 \mathrm{bp}$. For all reactions, 35 cycles were performed with annealing at $63^{\circ} \mathrm{C}$ for 30 seconds and extension at $72^{\circ} \mathrm{C}$ for 1 minute.

Statistical analysis was performed using Prism software (GraphPad) using a two-way analysis of variance. Quantitative PCR was performed for alternative splice form Anxa6 transcript using the primers described in $R T-P C R$ and Quantitative PCR Analysis. GAPDH was amplified using the following primers: GAPDHF, 5'-TTGTGATGGGTGTGAACCACGA-3'; GAPDHR, 5'-AGCCCTTCCACAATGCCAAAGT- $3^{\prime}$. For all reactions, 45 cycles were performed with annealing and extension at $60^{\circ} \mathrm{C}$ for 70 seconds total. Melt curves of the reaction products were 
obtained starting at $65^{\circ} \mathrm{C}$ and increasing to $95^{\circ} \mathrm{C}$ with a step size of $0.5^{\circ} \mathrm{C}$. Quantitative PCR data were analyzed by determining the relative expression of full-length or alternatively spliced Anxa6 transcripts in comparison to the reference gene (Gapdh), following the mathematical model from Pfaffl et al. ${ }^{32}$ Prism software (GraphPad) was used for performing a two-way analysis of variance.

\section{Electroporation, Fiber Preparation, and Laser Damage Assay}

The ANXA6-GFP plasmid was described previously. ${ }^{15}$ Flexor digitorum brevis fibers were transfected using methods similar to the in vivo electroporation methods described in detail previously. ${ }^{33,34}$ Briefly, the footpad was injected with $10 \mu \mathrm{L}$ of hyaluronidase $(8 \mathrm{U})$. Two hours after injection, up to $20 \mu \mathrm{L}$ of $2 \mu \mathrm{g} / \mu \mathrm{L}$ of endotoxin-free plasmid DNA was injected into the footpad between the muscle bundle and the epidermis. Voltage was applied. Muscle fibers were isolated and studied 7 days after electroporation to allow for recovery and efficient protein expression within the electroporated muscles. The flexor digitorum brevis muscle bundle was dissected and placed in Dulbecco's Modified Eagle's Medium containing bovine serum albumin plus collagenase solution. Dissociated fibers were plated on confocal microscopy dishes (P35G-1.5-14-C; MatTek, Ashland, MA). FM 4-64 dye (T-13320; Molecular Probes,
Eugene, OR) was added at $2.5 \mu \mathrm{mol} / \mathrm{L}$ before imaging. Fibers were irradiated using the region of interest point in the NIS Elements imaging software version 4.30 .02 (Nikon Instruments, Melville, NY) on the A1R confocal microscope (Nikon Instruments) using a 405-nm laser set at 100\% power for 5 seconds. Images were acquired before damage, on laser damage, every 2 seconds after damage for 20 seconds, and then one image every 10 seconds for 130 seconds. Images were quantified using ImageJ software $(\mathrm{NIH})$. For quantitative analysis of FM dye, fluorescence was measured at the site of injury in individual frames using ImageJ software (NIH) and adjusted to the baseline fluorescence at time 0 calculated at the membrane before damage $\left(F / F_{0}\right)$. Suboptimal fibers were excluded from the analysis. Statistical analysis was performed with Prism software (GraphPad) using an unpaired $t$-test.

\section{Serum CK Measurement}

Serum was collected from age-matched $D y s f^{129}$ and $D y s f^{B 6}$ animals from retro-orbital bleeds using heparinized capillary tubes (Fisher Scientific, Pittsburgh, PA) into serum separator tubes (Becton, Dickinson, and Company, Franklin Lakes, NJ) and centrifuged for 10 minutes at $8000 \times g$. The plasma fractions were frozen and stored at $-80^{\circ} \mathrm{C}$ and then assayed later using the EnzyChrom Creatine Kinase Assay Kit (ECPK-100; BioAssay Systems, Hayward, CA).
A

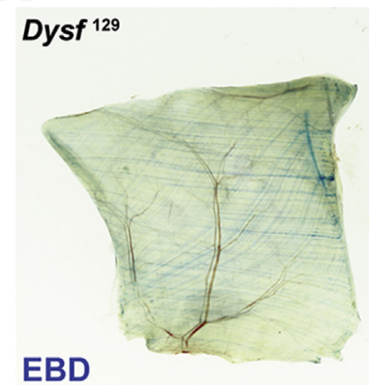

C

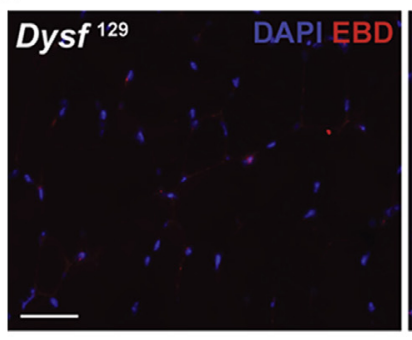

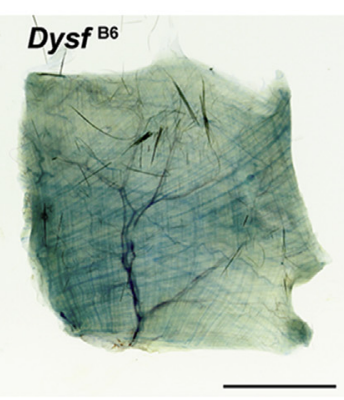

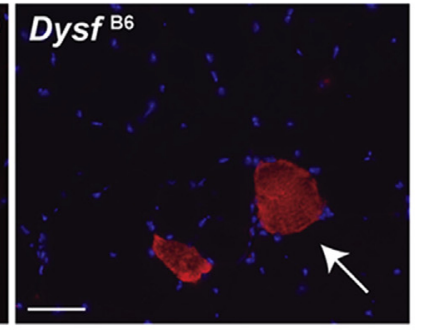

B

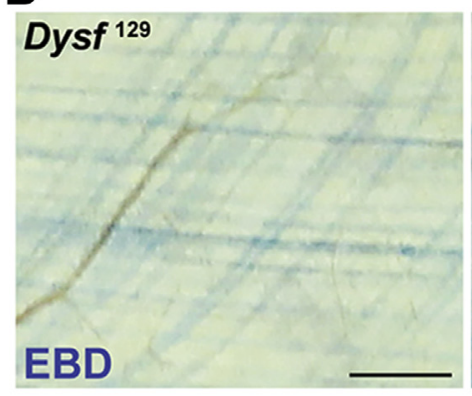

D

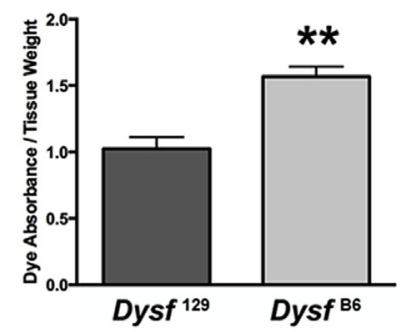

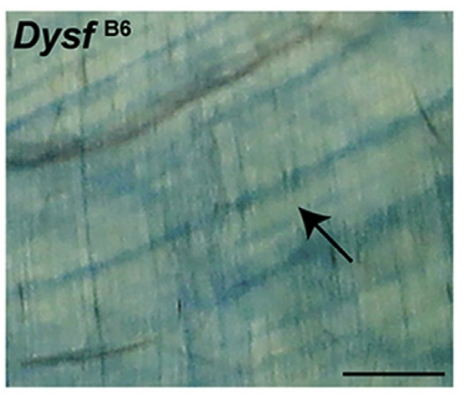

E

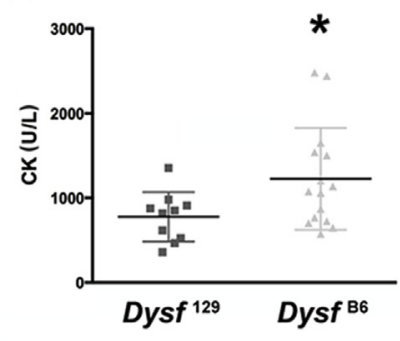

Figure 1 Myofiber leak is increased in $D y s f^{\beta 6}$ muscle compared to $D y s f^{129}$ muscle. A: Gross images of Evans Blue dye (EBD) uptake in abdominal muscle show increased EBD uptake (blue streaks) in Dys $f^{\beta 6}$ muscle. B: High-magnification images show that EBD uptake is increased in Dys $f^{B 6}$ myofibers (black arrow). C: Myofiber EBD uptake is increased (red; white arrow), a marker of muscle damage, in Dys $f^{\beta 6}$ quadriceps muscles. Nuclei were stained with DAPI. D: At 1 year of age, EBD uptake in quadriceps muscle is increased in $D y s f^{\beta 6}$ mice compared to age-matched Dysf $f^{129}$ mice. E: Serum creatine kinase (CK) is elevated, a marker of muscle damage, in Dys $f^{B 6}$ compared to Dys $f^{129}$. Data are expressed as means \pm SEM. $n=6$ mice per genotype (D); $n \geq 10$ mice per group (E). ${ }^{*} P<0.05$, $* * P<0.01$ versus Dysf ${ }^{129}$. Scale bars: $10 \mathrm{~mm}(\mathbf{A}) ; 1 \mathrm{~mm}(\mathbf{B}) ; 50 \mu \mathrm{m}(\mathbf{C})$. 

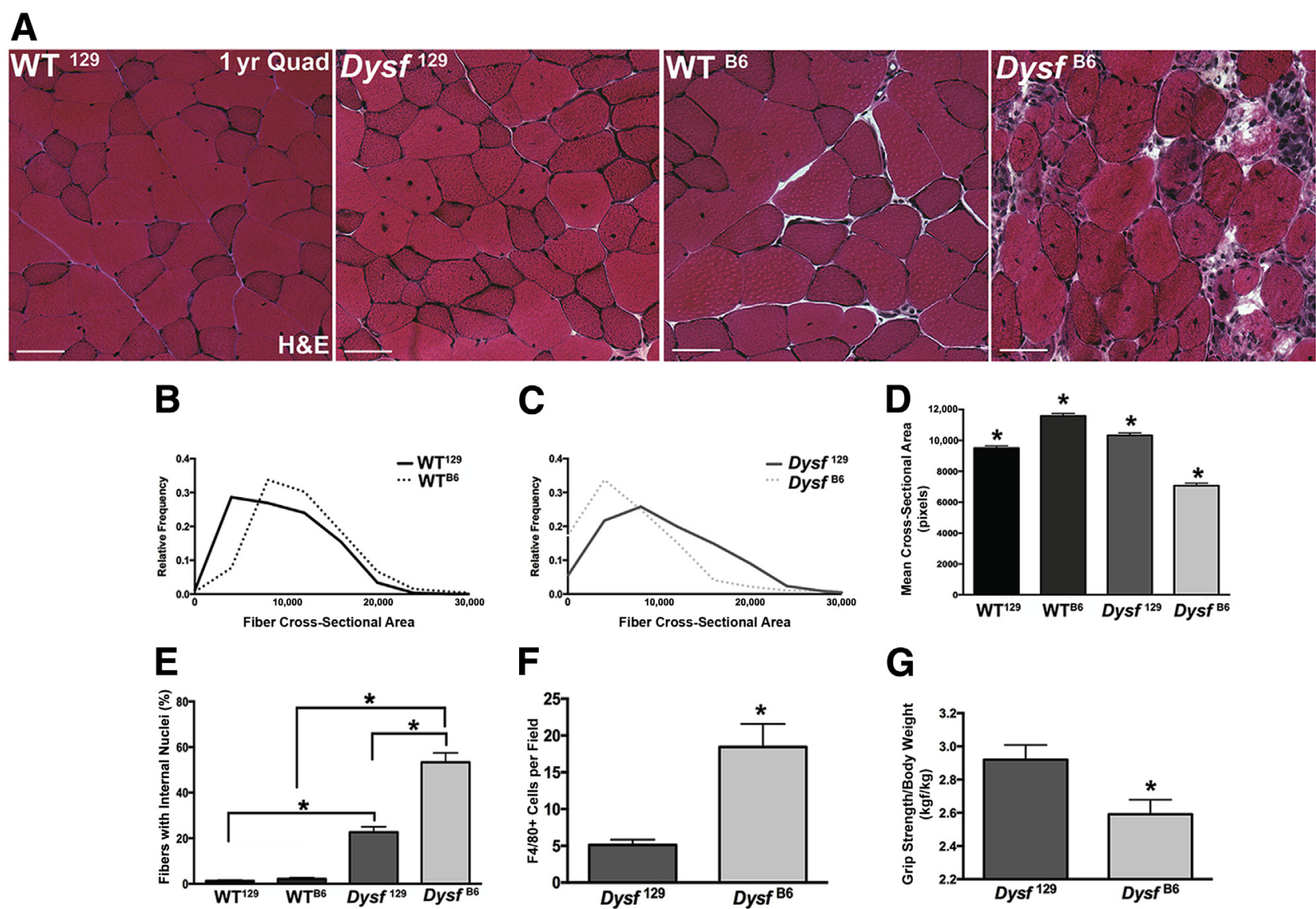

Figure 2 Histopathology is increased in $D y s f^{\beta 6}$ mice compared to $D y s f^{129}$ mice. A: Dys $f^{\beta 6}$ quadriceps (Quad) muscles display characteristic features of muscular dystrophy, including internalized nuclei, fibrosis, and immune infiltrate. B and C: The number of largest myofibers is reduced, and the number of smaller-sized fibers is increased, in B6 muscles in both wild-type (WT) and Dysf mutants. D: Cross-sectional area is reduced in Dysf $f^{129}$ and Dysf $f^{B 6}$ muscle compared with WT controls. Cross-sectional area is reduced in Dysf $f^{B 6}$ muscle, which expresses annexin A6N32, compared to Dys $f^{129}$ muscle. E: The percentage of myofibers with internalized nuclei is significantly increased in $D y s f^{\beta 6}$ muscle compared to both WT and Dysf $f^{129}$ muscle. F: Quantification of F4/80 cells shows an increased macrophage infiltrate per field in Dys $f^{\beta 6}$ muscle compared to Dysf $f^{29}$ muscle. G: Grip strength is reduced in Dys $f^{\beta 6}$ mice. Data are expressed as means \pm SEM (E-G). $n \geq 3$ mice per genotype $(\mathbf{B}-\mathbf{F}) ; n=9$ mice per genotype $(\mathbf{G})$. ${ }^{*} P<0.05$. Scale bars $=50 \mu \mathrm{m}$. H\&E, hematoxylin and eosin.

Activity was measured in the Synergy HTX Multi-Mode Microplate Reader (BioTek Instruments, Winooski, VT). Statistical analysis was performed with Prism software (GraphPad) using an unpaired $t$-test.

\section{Grip Strength Measurement}

Grip strength was assessed using a grip strength meter (Columbus Instruments, Columbus, $\mathrm{OH}$ ) consisting of a horizontal bar attached to a force meter. Forelimbs grip the bar in 10 consecutive measurements within 2 minutes. Forces were recorded and normalized to body weight as described previously. ${ }^{35}$ Statistical analysis was performed with Prism software (GraphPad) using an unpaired $t$-test.

\section{Results}

\section{Membrane Leak Is Increased in Dys $f^{\beta 6}$ Myofibers}

The AJ mouse strain housed at Jackson Laboratories carries a spontaneous retro-transposon insertion in intron 4 of the Dysf gene, causing a null allele of the Dysf gene and progressive muscular dystrophy. ${ }^{36}$ This Dysf allele was previously backcrossed to the $\mathrm{C} 57 \mathrm{BL} / 6$ and referred to as Bla/J. ${ }^{37}$ In separate studies, this same allele was backcrossed in the 129T2/SvEmsJ strain; herein these strains are referred to as $D y s f^{B 6}$ and $D y s f^{129}$, respectively. ${ }^{28,37}$ Although some properties of these mice have been reported individually, myopathic progression has not been directly compared between these two mouse strains. EBD uptake in muscle reflects myofibers that have increased sarcolemmal leak as well as degenerating fibers. Normal muscle is impermeable to this vital tracer, whereas muscular dystrophies with sarcolemmal defects display enhanced EBD uptake. ${ }^{31}$ EBD uptake was visually apparent in $D y s f^{\beta 6}$ muscle, seen as blue striations in the abdominal muscles (Figure 1A). A highermagnification image is shown in Figure 1B illustrating the presence of EBD following the myofiber pattern. By immunofluorescence microscopy, the quadriceps muscle showed increased numbers of EBD-positive myofibers compared to $D y s f^{129}$ muscle (Figure 1C). Whole quadriceps muscle was minced and EBD uptake was quantified; Dysf $f^{\mathrm{B}}$ muscle 
contained more EBD than did Dysf ${ }^{129}$ muscle $(P<0.01)$ (Figure 1D). Elevated serum CK is a marker of muscle injury and disease in both mice and humans, including the dysferlinopathies. ${ }^{38} D y s f^{B 6}$ mice had higher levels of serum CK compared to Dysf $f^{29}$ mice at 7 months, a time of early disease onset $(P<0.05)$ (Figure 1E). These data show that $D y s f^{B 6}$ muscle has increased myofiber leak, consistent with poor myofiber resealing, compared to Dysf ${ }^{129}$.

\section{Dysf $f^{B 6}$ Muscle Pathology in the C57BL/6J Background}

To determine whether the genetic background modifies muscle disease in the absence of dysferlin, muscle from both $D y s f^{129}$ and $D y s f^{86}$ mice were analyzed. Muscle from 52-week-old Dysf mice displayed characteristic myopathic features, including internalized nuclei, fibrosis, and immune infiltrate (Figure 2A). Dysf ${ }^{\mathrm{B} 6}$ muscles had an increased number of smaller-sized fibers and a reduction in largest myofibers compared to Dysf ${ }^{129}$ muscle and WT control (Figure 2, B and C). These data correlated with a reduction in the mean cross-sectional area. Both Dysf $f^{29}$ and Dysf $f^{\mathrm{B}}$ myofiber size were reduced compared to strain-matched controls, and $D y s f^{\beta 6}$ muscle also showed reduced crosssectional area compared to Dysf ${ }^{129}$ muscle $(P<0.05)$ (Figure 2D). Consistent with a more severe myopathic phenotype, $D y s f^{B 6}$ muscle contained an increased percentage of myofibers with internalized nuclei compared to both WT controls and Dysf $f^{129}$ muscle $(P<0.05)$ (Figure 2E). These data indicate that the phenotype of dysferlin-mediated muscular dystrophy is enhanced in the C57BL/6J background compared to the 129T2/SvEmsJ background.

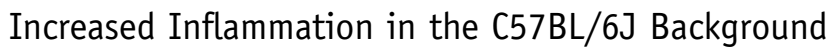

Inflammatory infiltration has been described in human muscle biopsy samples with DYSF mutations. ${ }^{3,39-41}$ Activated macrophages were increased in the SJL/J mouse model. ${ }^{42}$ F4/80 conjugated to Alexa Fluor 488 is a marker of activated macrophages, and F4/80 immunofluorescence imaging showed increased macrophage infiltration, represented as number of $\mathrm{F} 4 / 80^{+}$cells per field, in $D y s f^{\mathrm{B} 6}$ muscle compared to Dysf $f^{129}$ muscle $(P<0.05)$ (Figure $2 \mathrm{~F}$ ). The percentage of $\mathrm{F} 4 / 80^{+}$cells per total nuclei was also significantly increased in $D y s f^{\beta 6}$ muscle (data not shown). Furthermore, $D y s f^{\mathrm{B} 6}$ muscle represented as $\mathrm{F} 4 / 80^{+}$cells per fiber was also increased compared to $D y s f^{129}$ muscle (data not shown). Consistent with the increased pathology and membrane leak, an increased number of macrophages are present in muscle from the C57BL/6J background.

\section{Decreased Strength in Dysf $f^{B 6}$ Mice Compared to Dysf $f^{129}$ Mice}

To examine the effect of genetic background on muscle strength in combination with the loss of dysferlin, we examined grip strength. Dysf ${ }^{\mathrm{B} 6}$ mice had reduced grip
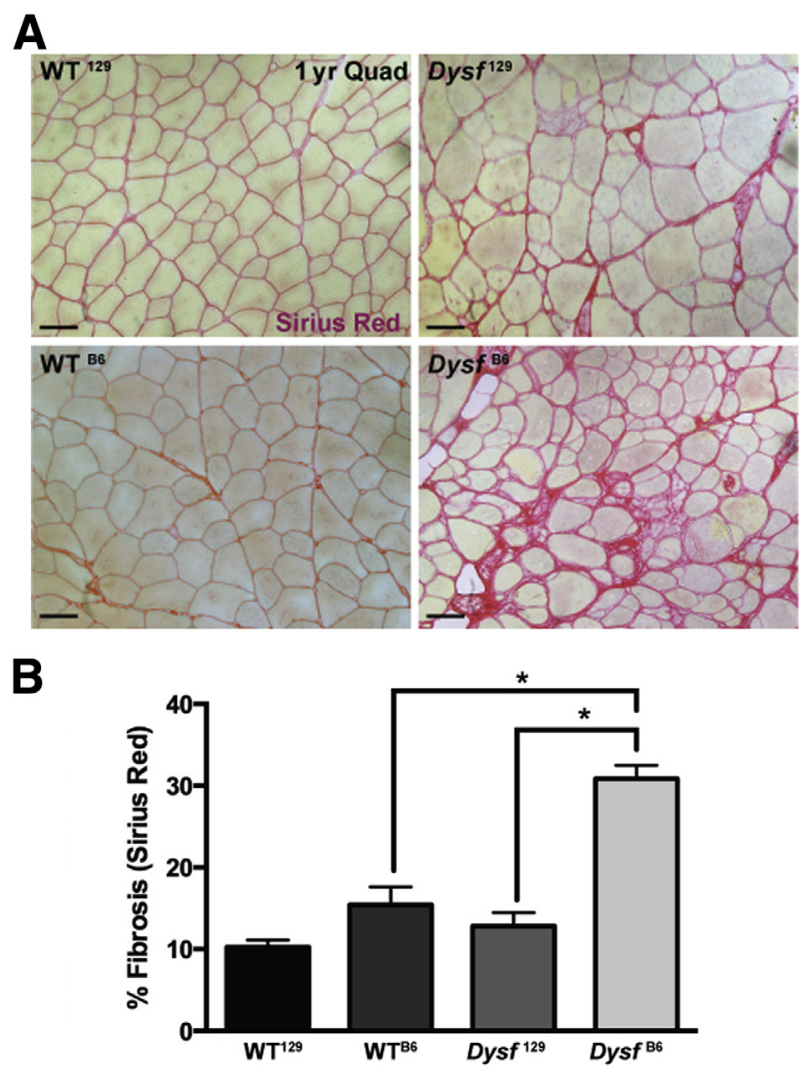

Figure 3 Fibrosis in skeletal muscle is increased in $D y s f^{\beta 6}$ compared to Dysf $f^{29}$. A: At 52 weeks, Picrosirius red staining in quadriceps (Quad) muscle is increased in $D y s{ }^{\beta 6}$. B: Quantification of collagen shows fibrosis that is greater in mice with the annexin $A 6 \mathrm{~N} 32\left(D y s f^{B 6}\right.$ and $W T^{B 6}$ ) than in mice with fulllength annexin A6 (Dysf $f^{129}$ and $\left.\mathrm{WT}^{129}\right)$. Data are expressed as means $\pm \mathrm{SEM}$. $n=3$ mice per genotype. ${ }^{\star} P<0.05$. Scale bars $=50 \mu \mathrm{m}$. WT, wild type.

strength when normalized to body weight compared to agematched and sex-matched Dysf $f^{129}$ mice (2.59 versus 2.92 $\mathrm{kgf} / \mathrm{kg}$, respectively; $P<0.05$ ) (Figure $2 \mathrm{G}$ ).

\section{$D y s f^{B 6}$ Muscle Has Increased Levels of Fibrosis Compared to Dysf ${ }^{129}$ Muscle}

Fibrosis, or the increase in interstitial collagen deposition, is a pathologic feature that is increased in many forms of muscular dystrophies. ${ }^{43}$ Muscle samples were stained with Picrosirius red and imaged to determine the fibrosis composition. At 52 weeks, $D y s f^{B 6}$ muscles had grossly increased Picrosirius red staining compared to Dysf ${ }^{29}$ muscle and WT controls (Figure 3A). The amount of Picrosirius red was quantified using ImageJ plug-in software (NIH). Dysf $f^{\mathrm{B} 6}$ muscle showed statistically elevated levels of fibrosis compared to Dysf ${ }^{129}$ muscle and WT controls $(P<0.05)$ (Figure 3B). These data show that the genetic background modifies fibrosis with increased muscle fibrosis in $D y s f^{B 6}$ mice compared to Dysf $f^{29}$ mice.

\section{Decreased Membrane Repair in Dysf $f^{\beta 6}$ Myofibers}

Dysferlin is a protein known to be required for efficient sarcolemmal repair, and a lack of dysferlin delays muscle 


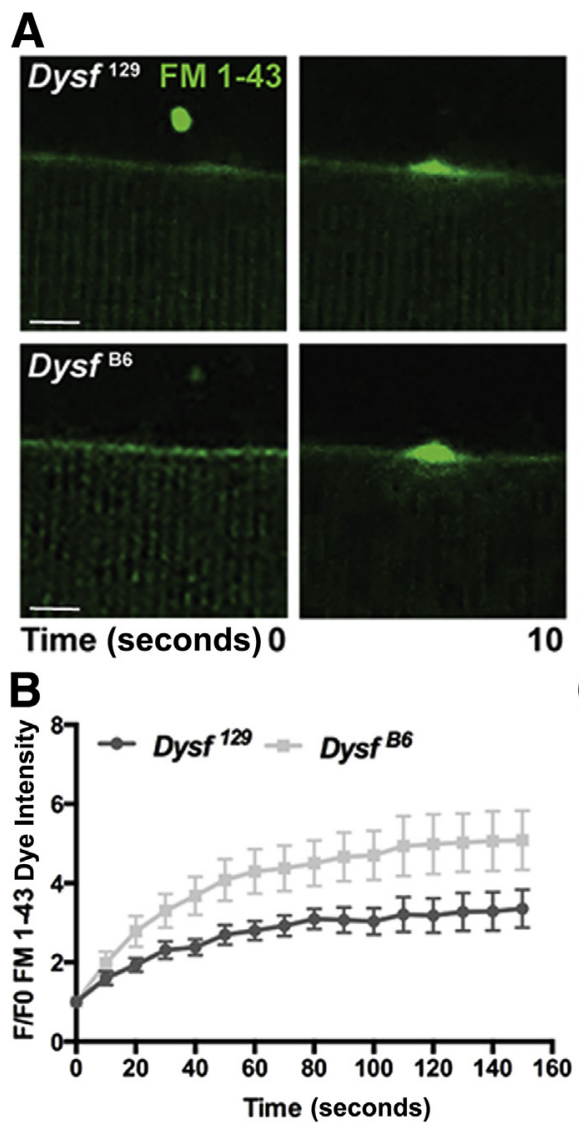

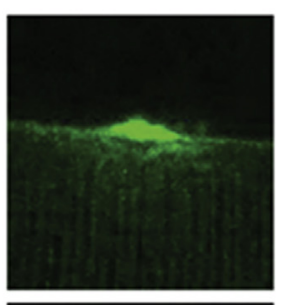
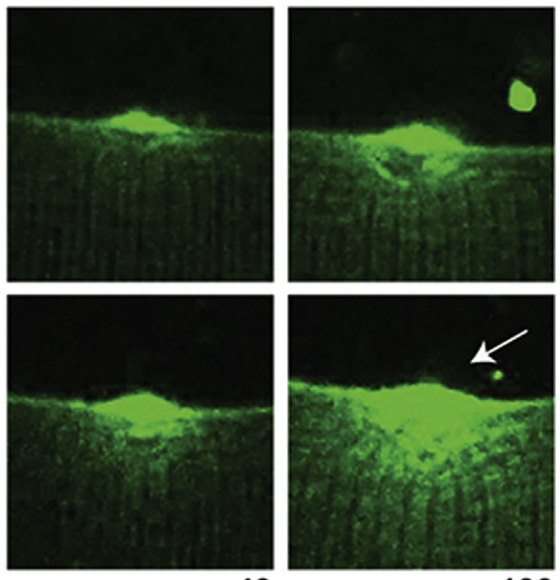

10

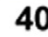

100
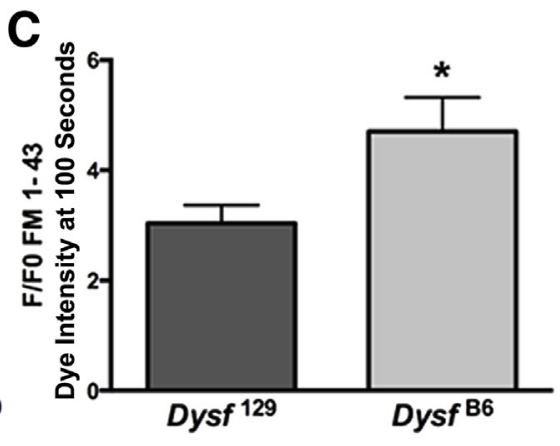

Figure $4 \quad$ B6 background contributes to plasma membrane repair in the absence of dysferlin. A: Myofibers from dysferlin-null mice (Dysf ${ }^{129}$ and $D y s f^{B 6}$ ) were isolated and subjected to laser-induced injury in the presence of FM 1-43. Representative images after injury demonstrate FM 1-43 uptake that is increased in $D y s{ }^{\beta 6}$ fibers (arrow). B: Over time, FM 1-43 uptake is increased in Dysf ${ }^{\beta 6}$ fibers compared to Dysf $f^{129}$ myofibers. C: At 100 seconds after damage, FM 1-43 dye uptake is significantly greater in $D y s f^{B 6}$ animals lacking Dysf and containing the A6N32 splice variant than in Dysf ${ }^{129}$ myofibers, which do not express the A6N32 splice variant at an appreciable level. Data are expressed as means \pm SEM. $n=3$ mice per genotype (B and C); $n \geq 7$ fibers isolated (B and C). ${ }^{*} P<0.05$. Scale bars $=4 \mu \mathrm{m}$. membrane resealing. ${ }^{7}$ We evaluated whether the genetic background alters membrane by conducting laser wounding on isolated myofibers from Dysf $f^{129}$ and $D y s f^{\mathrm{B} 6}$ mice in the presence of FM 1-43, a lipophilic dye that under normal conditions exhibits minimal fluorescence but increases fluorescence after damage as it binds the phospholipid membrane (Figure 4A). We hypothesized that if a difference is seen between these two strains, it is not due to the identical dysferlin lesion but due to another genetic variant that is distinct between these two background strains. After laser-induced membrane damage, FM 1-43 dye uptake was elevated over time in Dysf ${ }^{\mathrm{B} 6}$ myofibers compared to that in age-matched Dysf ${ }^{129}$ myofibers (Figure 4B). Myofibers lacking dysferlin on the C57BL/6J background had significantly elevated FM-dye influx at 100 seconds after injury $(P<0.05)$ (Figure $4 \mathrm{C})$. These data show that genetic background plays a distinct role in influencing the process of membrane repair in dysferlinopathies.

\section{Truncated Annexin A6 Is Expressed in Dysf ${ }^{B 6}$ Tissue}

Annexin A6 (A6) is a $68-\mathrm{kDa}$, atypical annexin that contains eight annexin repeats split by a hinge region. Anxa6, encoding annexin A6, was recently found to modify muscular dystrophy caused by mutant $\gamma$-sarcoglycan, a protein that mediates membrane stability. ${ }^{15}$ Specifically, the DBA2J strain was shown to harbor a cryptic A-to-G splice site in Anxa6. This allele results in a truncated annexin A6 protein product of approximately $32 \mathrm{kDa}$, predicted to contain the first four annexin repeat domains (Figure 5A). The region of chromosome 11, which harbors the Anxa6 gene, is shared between the DBA2J and C57BL/ $6 \mathrm{~J}$ strains, but is not shared by the 129T2/SvEmsJ strain. Sanger sequencing confirmed that both the $\mathrm{WT}^{\mathrm{B} 6}$ and Dysf $f^{\mathrm{B} 6}$ background strains contained the $\mathrm{G}$ variant in Anxa6, resulting in the altered cryptic splice donor, whereas the $\mathrm{WT}^{129}$ and Dysf $f^{129}$ contained the A nucleotide (Figure 5B). Immunoblot analysis was performed with an antibody against the amino-terminus of annexin A6 that recognizes both the full-length annexin A6 protein and the truncated annexin A6 protein (A6N32) (Figure 5C). The expression of full-length annexin A6 protein was twofold greater in Dysf-null muscle compared to WT in both genetic backgrounds, whereas the expression of A6N32 was 20-fold greater in Dysf ${ }^{\mathrm{B} 6}$ muscle compared to Dysf $f^{129}$ muscle (Figure 5, C and D). Total protein bands running near $43 \mathrm{kDa}$ are shown as a loading control. This low-level expression of A6N32 protein was comparable to that previously observed in the DBA2J background in Sgcg-null muscle. $^{15}$

To examine how the presence of the single-nucleotide polymorphism in Anxa6 alters annexin A6 transcript expression, RT-PCR was performed on RNA isolated from abdominal muscle samples from $\mathrm{WT}^{129}, \mathrm{WT}^{\mathrm{B} 6}$, 


\section{Dysferlin}

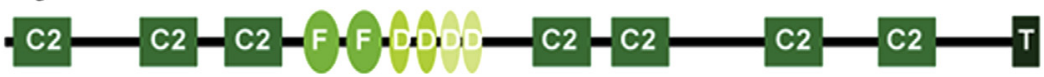

B
129
AGT AT TT T GCAGAAAGGCT GT T C WT WT $^{129}$ AGT AT T T T GCA GAAA GGCT GT T C Dysf 129
B6 | AGT AT T T T GC GGAAAGGCT GT T C WT'B6 AGT AT T T T GC GGAAA GGCT GT T C Dysf ${ }^{\mathrm{B} 6}$

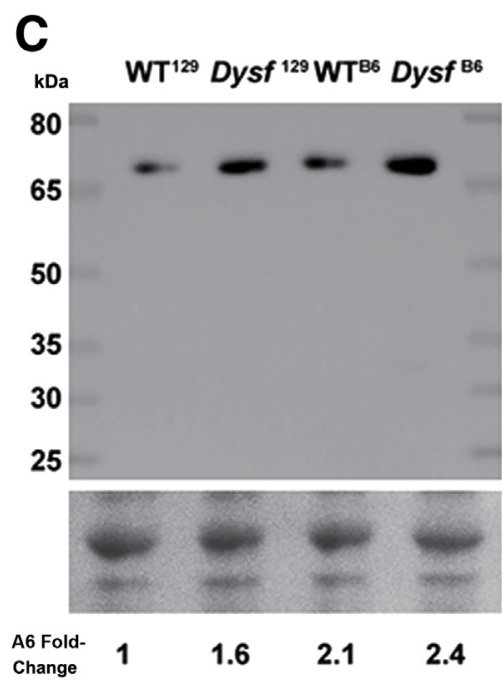

D

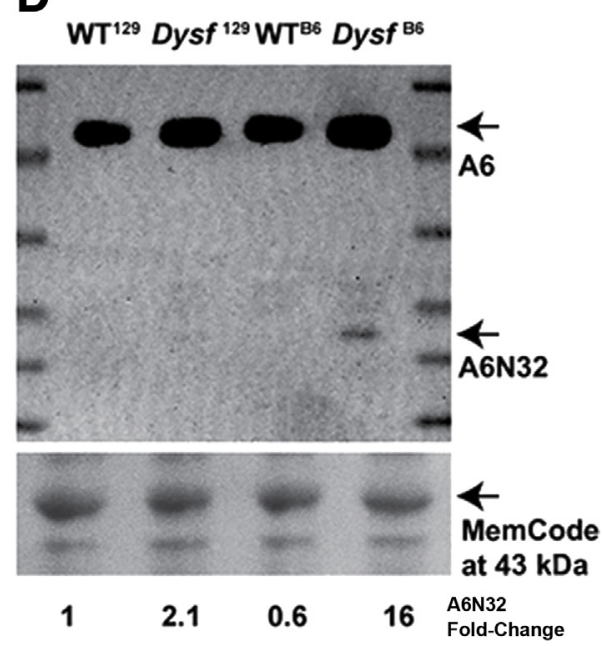

Figure 5 Dysferlin and annexin A6 (A6) are involved in skeletal muscle membrane repair. A: Annexin $\mathrm{A} 6$ is a $68-\mathrm{kDa}, \mathrm{Ca}^{2+}$-dependent membrane binding protein that contains eight annexin repeats. Annexin A6N32 (A6N32) is a $32-k D a$, truncated splice form of the annexin A6 protein. Dysferlin is a $237-\mathrm{kDa}$, calcium-dependent phospholipid-binding protein that contains seven C2 domains and a carboxyl-terminal transmembrane domain. B: Sanger sequencing confirms the singlenucleotide polymorphism (G) in Anxa6 in wild-type $(\mathrm{WT})^{\mathrm{B} 6}$ and $D y s f^{\beta 6}$ mouse strains. This sequence is associated with the alternative Anxa6 transcript that encodes A6N32. ${ }^{15}$ C: Immunoblot analysis with the anti-annexin A6 antibody recognizes full-length annexin $A 6$ and A6N32. Low-exposure imaging demonstrates that full-length annexin A6 is more highly expressed in Dysf-null mice compared to strain-matched WT controls. D: On longer exposure, annexin A6N32 is visible (arrows) in $D y s f^{B 6}$ muscle lysates. The $43-\mathrm{kDa}$ protein band was used as a loading control using MemCode reversible stain (Thermo Fisher Scientific, Rochester, NY).
$D y s f^{129}$, and Dysf ${ }^{\mathrm{B} 6}$ mice. Previously these singlenucleotide polymorphisms were associated with the presence of an alternative transcript that joins the middle of exon 11 to the middle of exon 15 , resulting in a premature stop codon. ${ }^{15}$ Primers designed to detect both full length and the alternative transcript and primers specific to only the alterative splice product were individually tested. Products of expected size were observed, and qualitatively, C57BL/6J muscle expressed an increased amount of alternative transcript compared to 129T2/ SvEmsJ muscle (Figure 6A). To quantify the difference in transcript expression, abdominal muscle from WT and mutant mice in the two backgrounds was compared by quantitative PCR. $\mathrm{WT}^{\mathrm{B} 6}$ and $D y s f^{\mathrm{B} 6}$ muscle contained significantly increased amounts of full-length and alternative transcripts compared to mice on the 129 background $(P<0.05)$ (Figure 6, B and $\mathrm{C}$ ). RNA isolated from tibialis anterior muscle generated annexin A6 and A6N32 transcript profile patterns similar to those generated from abdominal muscle $(P<0.05)$ (Figure 6 , $\mathrm{D}$ and $\mathrm{E}$ ).
Dysf ${ }^{B 6}$ Myofibers Have Delayed Annexin A6

Translocation to Sites of Sarcolemmal Disruption Compared to Dysf $f^{129}$ Myofibers

Given the more severe pathology of the Dysf ${ }^{\mathrm{B} 6}$ mouse model compared to the Dysf ${ }^{129}$ model, we assessed the effect of genetic background on full-length annexin A6 translocation in the absence of dysferlin. Delayed annexin A6 translocation was previously observed when truncated annexin A6, A6N32, was introduced into $\mathrm{WT}^{129}$ myofibers. ${ }^{15}$ Overexpression of exogenous A6N32 reduced the formation of annexin A6 aggregates at the site of injury, and is associated with increased FM dye influx. ${ }^{15}$ To examine whether the genetic background altered annexin A6 translocation to the site of injury, annexin A6-GFP plasmid was electroporated in $D y s f^{\mathrm{B} 6}$ or $D y s f^{129}$ muscles followed by harvest and live cell imaging after laser-induced sarcolemmal wounding. In Dysf $f^{29}$ myofibers, full-length annexin A6 translocated rapidly to the membrane, forming a tight aggregation at the site of laser wounding, similar to previous findings observed in WT fibers. ${ }^{15}$ With differential 
A

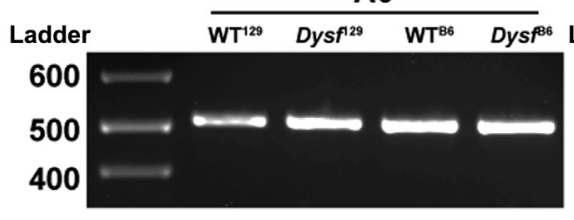

A6

B

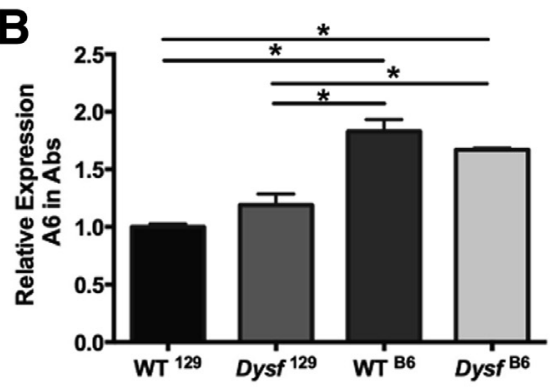

D

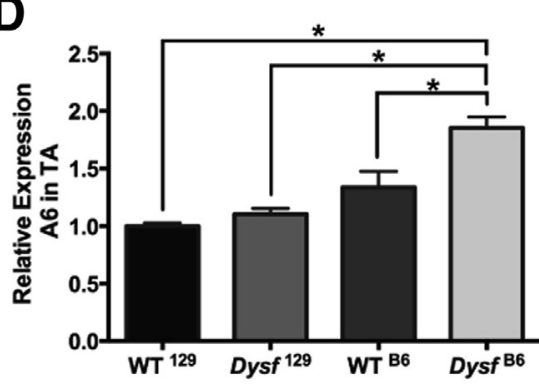

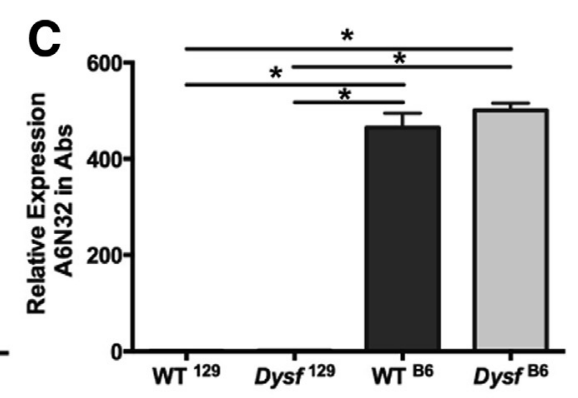

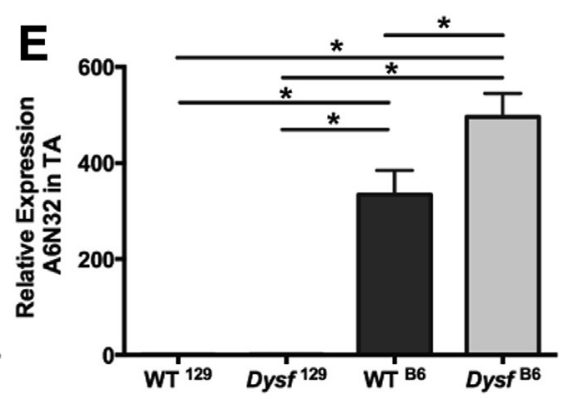

A6N32

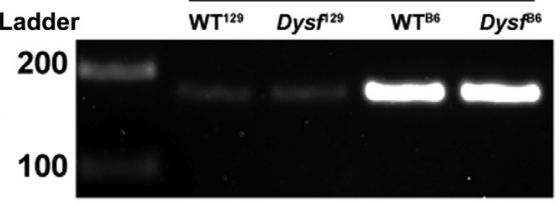

Figure 6 Annexin A6 (A6) transcripts are expressed differentially between the B6 and 129 mouse strains. Annexin A6 is highly expressed in muscle. A single-nucleotide polymorphism in the B6 genome results in an alternative splice variant of annexin A6, A6N32. A: RT-PCR shows amplification of full-length annexin A6, running at 515 $\mathrm{bp}$, in both backgrounds. Primers specific for the A6N32 splice form show increased amplification in the B6 background, running at 174 bp. B: Quantitative PCR from abdominal muscle shows expression of full-length annexin $A 6$ that is significantly increased on the B6 strains compared to the 129 strains in both wild-type (WT) and Dysf mice. C: By quantitative PCR from abdominal muscle, A6N32 transcripts are increased in $\mathrm{WT}^{\mathrm{B} 6}$ and $D y s f^{B 6}$ mice compared to mice on the 129 background. D: Similar to findings in abdominal muscle, quantitative PCR from tibialis anterior (TA) muscle shows expression of full-length annexin $A 6$ that is significantly increased on the B6 strains compared to the 129 strains in both WT and Dysf mice. E: In TA muscle, A6N32 transcripts are increased in $W T^{B 6}$ and $D y s f^{B 6}$ mice compared to $W^{129}$ and Dysf ${ }^{129}$ mice. Data are expressed as means \pm SEM. $n=3$ mice per genotype. ${ }^{*} P<0.05$. Abs, abdominal muscle. interference contrast imaging, accumulation of annexin A6 was observed at the site of injury associated with the myofiber (Figure 7A). In contrast, translocation of annexin A6-GFP was reduced in Dysf ${ }^{\mathrm{B} 6}$ myofibers (Figure 7A). The reduced size of the A6 aggregate in Dysf $f^{\mathrm{B} 6}$ myofibers is visible in the confocal Z-stack projections (Figure 7B). At 150 seconds after wounding, the size of the $D y s f^{\mathrm{B} 6}$ annexin A6 aggregate at the site of laser wounding was significantly reduced compared to that observed in Dysf $f^{129}$ myofibers $(P<0.01)$ (Figure $7 \mathrm{C})$. The presence of a genetic background that expressed A6N32 inhibited the translocation of full-length annexin A6 in Dysf-null muscle.

\section{Ltbp4 Does Not Modify Dysferlin-Mediated Muscular Dystrophy}

Like Anxa6, Ltbp4, encoding the latent transforming growth factor $\beta$-binding protein 4 , was similarly identified in a genome-wide scan for modifiers of muscular dystrophy in which an insertion/deletion polymorphism alters the prolinerich hinge region of the Ltbp4 protein. ${ }^{44}$ Notably, LTBP4 also modifies years of ambulation in human Duchenne muscular dystrophy. ${ }^{45}$ In inbred mouse strains, the insertion allele is more common. ${ }^{44}$ The DBA2J strain harbors the deleterious $L t b p 4$ deletion allele $\left(L t b p 4^{\mathrm{d} / \mathrm{d}}\right)$. The deleterious $L t b p 4^{\mathrm{d} / \mathrm{d}}$ allele was backcrossed into the $D y s f^{129}$ mouse strain, generating congenic Dysf $f^{129}$ mice with, Dysf $f^{29} ; L t b p 4^{\mathrm{i} / \mathrm{i}}$, and without, Dysf ${ }^{129} ; L t b p 4^{\mathrm{d} / \mathrm{d}}$. The pathology in these two lines was compared in mice $\geq 6$ months of age. Both $D y s f^{129} ; L t b p 4^{\mathrm{d} / \mathrm{d}}$ and $D y s f^{129} ; L t b p 4^{\mathrm{i} / \mathrm{i}}$ muscle displayed characteristic myopathic features of dysferlinopathy, including internalized nuclei, variable fiber size, and immune infiltrate (Figure 8A). However, the presence of $L t b p 4^{\mathrm{d} / \mathrm{d}}$ did not change the percentage of myofibers with internalized nuclei (Figure 8B). Fibrosis was assessed through Masson's trichrome staining. No evidence of increased fibrosis was attributable to the Ltbp4 polymorphism (Figure 8C). Membrane leak was assayed through EBD uptake. Dysf ${ }^{129} ; L t b p 4^{\mathrm{d} / \mathrm{d}}$ muscle contained an amount of EBD uptake similar to that of Dysf ${ }^{129} ; L t b p 4^{i / i}$ muscle (Figure 8D). These data suggest that the presence of the $L t b p 4^{\mathrm{d} / \mathrm{d}}$ did not intensify Dysf-mediated muscular dystrophy in mice, unlike the annexin-dysferlin interaction, which mediates muscle disease progression.

\section{Discussion}

\section{Genetic Modifiers of Dysferlinopathy}

Muscular dystrophy is defined as a progressive loss of muscle fibers that outpaces the ability for muscle regeneration. Muscle tissue is generally replaced with fibrosis and fatty infiltration, resulting in progressive muscle weakness. To date, over 40 genes have been established as primary gene mutations resulting in dystrophy. Despite the identification of a large number of disease-causing genes, phenotypic outcome associated with a genetic lesion is 

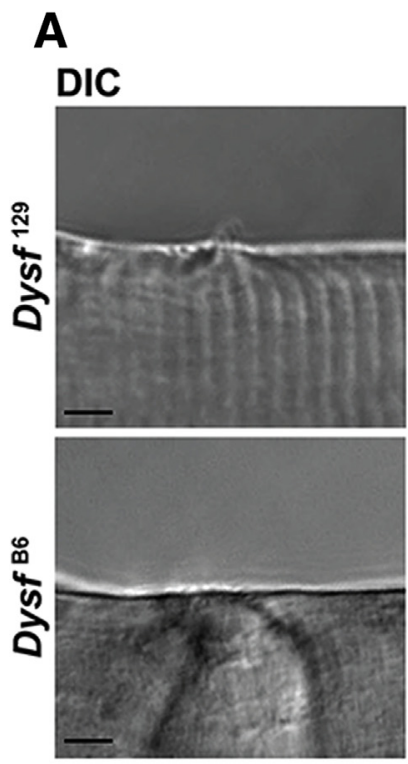

B

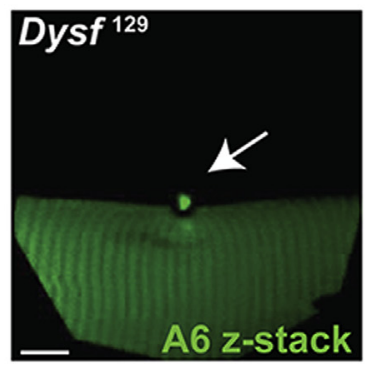

A6
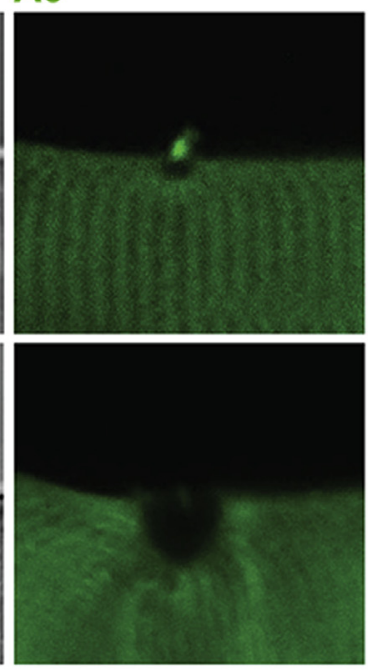

\section{Merge}
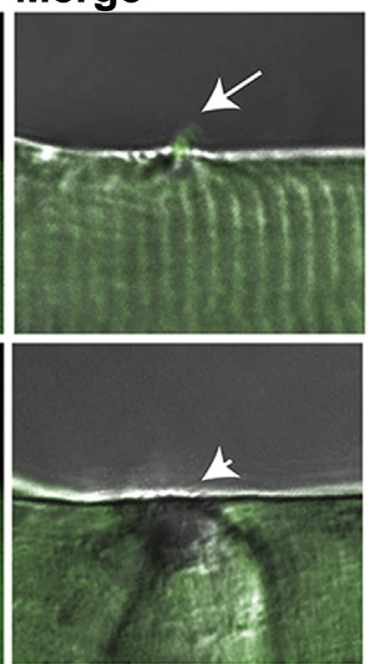

C

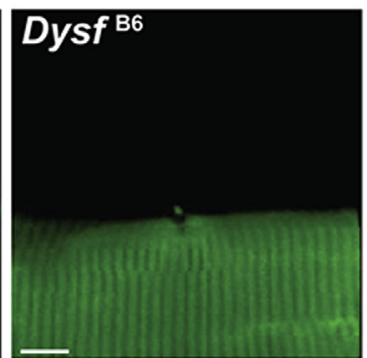

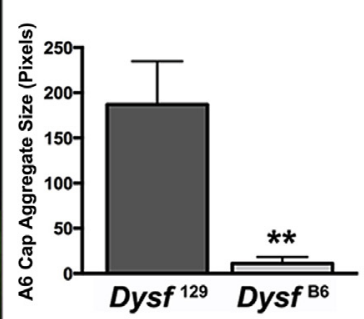

Figure 7 Reduced full-length annexin A6 (A6) translocation during membrane repair in $D y s f^{B 6}$. null myofibers. Dysf $f^{129}$ and Dysf ${ }^{\beta 6}$ myofibers were electroporated with annexin A6-GFP plasmid, followed by harvest and live cell imaging after laser ablation. A: In Dysf $f^{129}$ myofibers, annexin A6 (green) translocated rapidly to the site of laser disruption, forming a tight aggregate over the site of disruption (long arrow, $\mathbf{A}$ and $\mathbf{B}$ ), as seen in the merged differential interference contrast (DIC) image. In contrast, in $D y s f^{B 6}$ myofibers that endogenously express A6N32, annexin A6 (green) translocated less well, forming a smaller-sized aggregate (short arrow) at the site of membrane disruption. These data indicate that annexin A6 translocation occurred in the absence of dysferlin. B: On Z-stack projections of injured myofibers, the size of the $A 6$ aggregate is reduced in $D y s f^{B 6}$ compared to Dysf $f^{129}$ myofibers. C: The size of the A6 aggregate is reduced in $D y s f^{B 6}$ myofibers compared to Dysf $f^{129}$ myofibers. Data are expressed as means \pm SEM. $n=3$ mice per genotype (C); $n \geq 8$ fibers isolated $(\mathrm{C}) .{ }^{* *} P<0.01$. Scale bars: $4 \mu \mathrm{m}(\mathbf{A}) ; 8 \mu \mathrm{m}$ (B). variable, with a range of age of onset, timing of loss of ambulation, and muscle group involvement. Genetic modifiers act in combination with the primary genetic mutation to influence the outcome or severity of disease. Herein, we utilized two mouse strains harboring the same dysferlin loss-of-function mutation on two different backgrounds, Dysf $f^{\mathrm{B} 6}$ and $D y s f^{129}$. There are many genetic differences between these strains that can contribute to disease phenotype. In a strict sense, genetic modifiers should have little effect on basal phenotypes, but should instead manifest their effect in the context of disease or other primary phenotype.

\section{A}

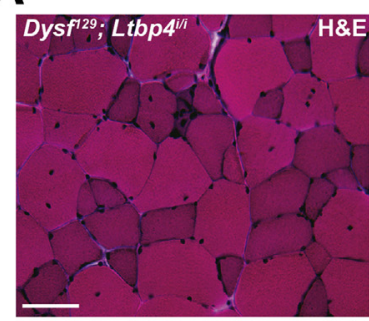

C

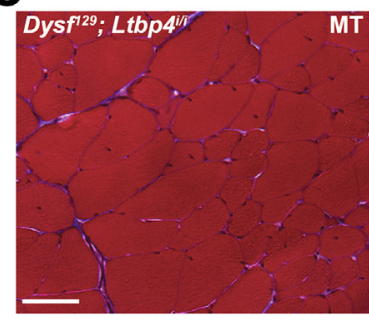

\section{B}
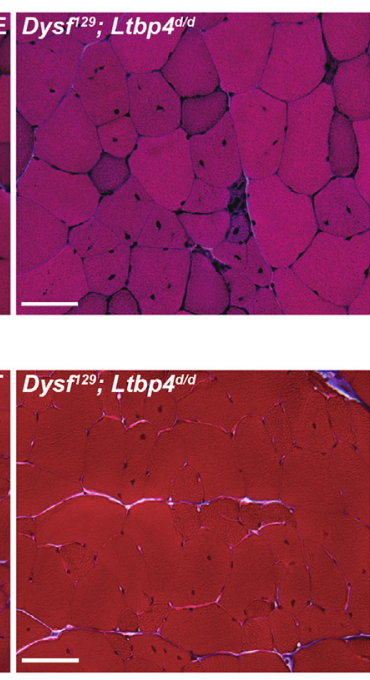

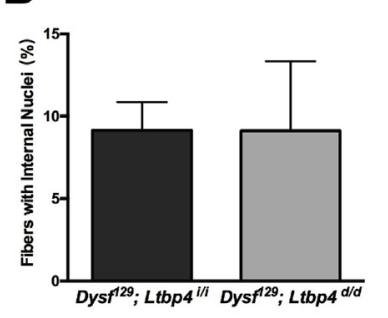

D

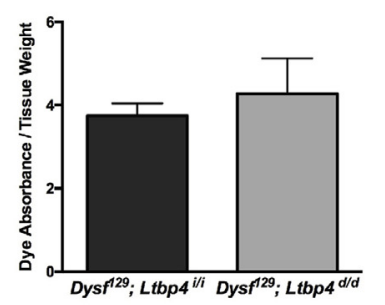

Figure 8 Ltbp4 does not alter Dysf histopathology or permeability. We have shown previously that Ltbp 4 modifies muscular dystrophy in both mice and humans. ${ }^{44,45}$ Congenic mice were generated that carry the previously identified Ltbp 4 modifier allele $\left(L t b p 4^{\mathrm{d} / \mathrm{d}}\right)$ on the Dysf $f^{129}$ background. A: Dysf quadriceps muscles with $\left(D y s f^{129} ;\right.$ Ltbp $4^{\mathrm{i} / \mathrm{i}}$ ) and without $\left(D y s f^{129} ; L t b p 4^{\mathrm{d} / \mathrm{d}}\right)$ the Ltbp 4 deletion allele display characteristic features of muscular dystrophy, including internalized nuclei, fibrosis, and immune infiltrate, at $\geq 6$ months. B: The percentage of myofibers with internalized nuclei is similar between Dysf ${ }^{129} ;$ Ltbp $4^{\mathrm{d} / \mathrm{d}}$ muscle and Dysf $f^{29} ;$ Ltbp $4^{\mathrm{i} / \mathrm{i}}$ muscle. C: Masson's trichrome (MT) staining, marking collagen content blue, is similar in quadriceps muscle at $>6$ months. D: In abdominal muscle, Evans Blue dye uptake is similar between Dysf $f^{129} ;$ Ltbp $4^{\mathrm{d} / \mathrm{d}}$ and age-matched $D y s f^{129} ; L t b p 4^{i / i}$ mice. Data are expressed as means \pm SEM. $n \geq 4$ mice per genotype $($ A-C) $; n \geq 8$ mice per genotype (D). Scale bars $=50$ $\mu \mathrm{m}$. H\&E, hematoxylin and eosin. 

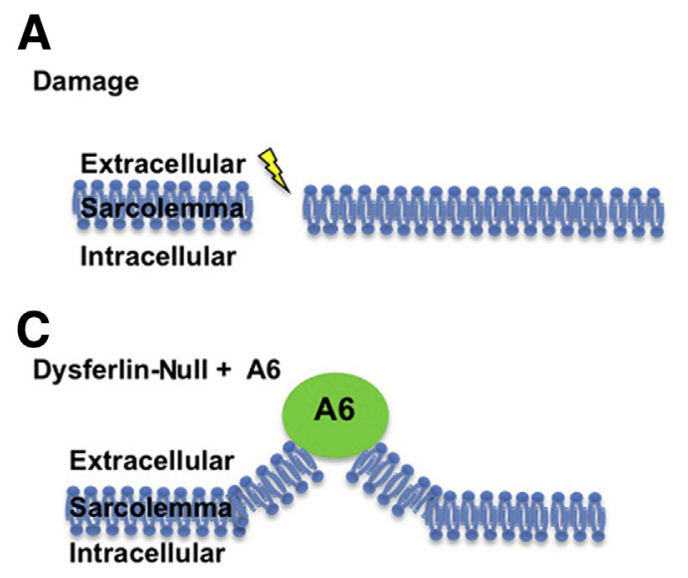

B

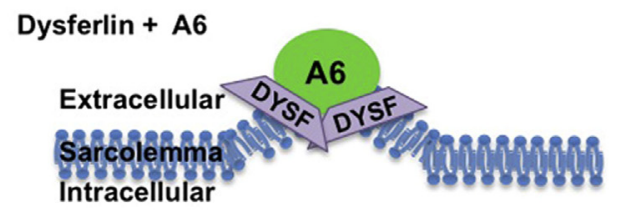

D

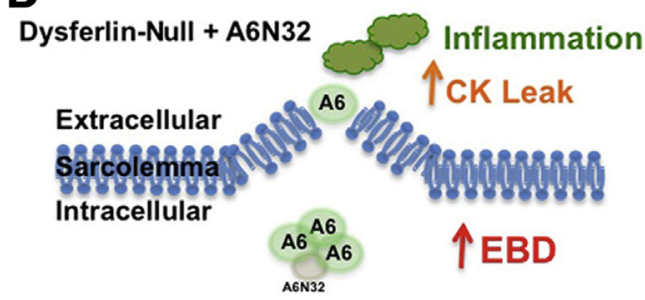

Figure 9 Schematic model for the annexin-dysferlin interaction. A and B: After membrane damage (A), annexin A6 (A6) aggregates at the site of disruption (B). Dysferlin (DYSF) has previously been shown to be recruited to sites of membrane damage. ${ }^{7}$ C: In the absence of dysferlin, annexin A6 is still recruited to the sarcolemma injury site. D: However, in the presence of truncated A6N32, annexin A6 forms smaller aggregates, and there is more membrane leak, resulting in increased inflammation and creatine kinase (CK) leak. EBD, Evans Blue dye.

We previously mapped two genetic modifiers of muscular dystrophy, Ltbp4 and Anxa6, in mice lacking the dystrophin-associated protein $\gamma$-sarcoglycan. ${ }^{15,44}$ Here, we evaluated the contribution of the Ltbp4 modifier using a congenic approach, but found no discernable effect in mice lacking dysferlin. This observation does not exclude an interaction between Ltbp 4 and dysferlinopathy, but certainly the findings suggest that any effect from this locus is modest at best. The Ltbp 4 polymorphism acts by regulating latent transforming growth factor $\beta$ release and its ability to interact with cell surface receptors triggering an increase in intracellular transforming growth factor $\beta$ signaling. Elevated transforming growth factor $\beta$ levels are associated with dystrophin-linked dystrophy, and this finding may suggest that transforming growth factor $\beta$-mediated responses have less effect in dysferlin deficiency. The observed decreases in SMAD3 and SMAD4 in dysferlinopathy are consistent with this observation. ${ }^{46}$

At the same time, we took advantage of the availability of the dysferlin-null allele in two genetic backgrounds, C57BL/6J and 129T2/SvEmsJ. By multiple measures, the C57BL/6J background enhances or intensifies the loss of dysferlinopathy, confirming that this is a better model for evaluating the relatively slowly progressive form of muscular dystrophy in mice. Mapping the modifier loci in dysferlinopathy requires substantial intercrossing of these genetic backgrounds, and this mapping is hampered by a late-onset phenotype in dysferlinopathic mice.

\section{Annexin A6 Translocation to Sites of Sarcolemmal Disruption Is Delayed in the $\mathrm{C} 57 \mathrm{BL} / 6 \mathrm{~J}$ Background}

There are substantial data to support an interaction between dysferlin and the annexin complex. Annexins A1 and A2 were previously observed to interact with dysferlin. ${ }^{21}$
Furthermore, a genetic interaction was previously observed in zebrafish engineered with both dysferlin and Anxa6 alleles. ${ }^{16}$ Muscular dystrophy has a distinct presentation in zebrafish compared to mammalian muscle, owing to the shorter lifespan and less fibrous replacement than that normally observed in mammalian muscle disease. We previously introduced the truncated annexin A6, A6N32, into 129T2/ SVEmsJ muscle, which lacks appreciable expression of this truncated protein. ${ }^{15} \mathrm{We}$ found that low-level expression of A6N32 produced a phenotype of delayed annexin A6 trafficking akin to what we now observe in $D y s f^{\beta 6}$ muscle, with a similar delay in translocation and the same reduced size of annexin A6 aggregates at the site of injury. We found that $D y s f^{B 6}$ mice, which harbor the deleterious Anxa6 allele, express the truncated protein product, A6N32. In this genetic background, there was enhancement of the muscular dystrophy phenotype and reduced translocation of annexin A6 to sites of sarcolemmal disruption.

Gene mutations that disrupt either sarcolemmal stability or sarcolemmal repair result in increased cellular permeability. A leaky plasma membrane allows for the influx of $\mathrm{Ca}^{2+}$ as well as efflux of cytoplasmic contents, eventually leading to cellular dysfunction and death if not repaired by the resealing machinery. CK leak from muscle into serum is a general phenomenon; recent studies suggest that a number of muscle proteins leak into serum, including titin, malate dehydrogenase 2, carbonic anhydrase III, and myosin heavy chain $1 .^{47,48}$ The absence of dystrophin renders the sarcolemma fragile and susceptible to injury, whereas the loss of dysferlin impairs membrane trafficking, including that associated with resealing of sarcolemmal disruptions. The observation of increased FM dye leak in $D y s f^{B 6}$ compared to $D y s f^{129}$ fibers is consistent with the elevated serum CK and also is consistent with the molecular signature of delayed resealing observed in the wounding assay. The degree to 
which delayed sarcolemmal repair contributes to dysferlinmediated pathology has been questioned, because repair does still occur in the absence of dysferlin. ${ }^{18}$

Annexins are known to homo- and hetero-oligomerize, and we hypothesize that low levels of A6N32 inhibit the formation of higher-order annexin structures that are needed to orchestrate efficient resealing. ${ }^{49}$ Although annexins A1 and A2 have been shown to interact with dysferlin, ${ }^{21}$ a direct interaction between annexin A6 and dysferlin is not required for this inhibition if the larger annexin structure is abnormal. We previously showed co-localization between dysferlin and annexin A6 in muscular dystrophy, ${ }^{15}$ but we expect that this interface includes a complex and dynamic set of interactions regulated by $\mathrm{Ca}^{2+}$ and lipid content (Figure 9).

\section{Annexins and Inflammation}

DYSF gene mutations have been described with an increased macrophage infiltrate in muscle, suggesting that impaired trafficking and perhaps myofiber leak account for increased inflammation. ${ }^{3,9}$ Dysf-null myofibers have increased leak, and this leak is an important signal for recruiting inflammatory cells. ${ }^{50}$ Roche et al ${ }^{10}$ showed that the Dysf-null mice on the AJ background have increased macrophage infiltration and muscle damage after large strain injury compared to A/WySnJ controls. Annexins, especially annexin $\mathrm{A} 1$, are linked to inflammation. ${ }^{24}$ Annexins are known to be cleaved and secreted; however, the exact mechanism by which annexins are externalized remains unknown because annexins lack an externalization sequence. ${ }^{51-53}$ Kamal et $\mathrm{al}^{54}$ showed that A6 192 , lacking six of the eight annexin domains, was also sufficient for blocking the function of full-length A6 in fibroblast endocytosis and exocytosis, further confirming that truncated annexin A6 can exert a dominant-negative role.

\section{References}

1. Bashir R, Britton S, Strachan T, Keers S, Vafiadaki E, Lako M, Richard I, Marchand S, Bourg N, Argov Z, Sadeh M, Mahjneh I, Marconi G, Passos-Bueno MR, Moreira Ede S, Zatz M, Beckmann JS, Bushby K: A gene related to Caenorhabditis elegans spermatogenesis factor fer-1 is mutated in limb-girdle muscular dystrophy type 2B. Nat Genet 1998, 20:37-42

2. Liu J, Aoki M, Illa I, Wu C, Fardeau M, Angelini C, Serrano C, Urtizberea JA, Hentati F, Hamida MB, Bohlega S, Culper EJ, Amato AA, Bossie K, Oeltjen J, Bejaoui K, McKenna-Yasek D, Hosler BA, Schurr E, Arahata K, de Jong PJ, Brown RH Jr: Dysferlin, a novel skeletal muscle gene, is mutated in Miyoshi myopathy and limb girdle muscular dystrophy. Nat Genet 1998, 20:31-36

3. Illa I, Serrano-Munuera C, Gallardo E, Lasa A, Rojas-Garcia R, Palmer J, Gallano P, Baiget M, Matsuda C, Brown RH: Distal anterior compartment myopathy: a dysferlin mutation causing a new muscular dystrophy phenotype. Ann Neurol 2001, 49:130-134

4. Anderson LV, Davison K, Moss JA, Young C, Cullen MJ, Walsh J, Johnson MA, Bashir R, Britton S, Keers S, Argov Z, Mahjneh I, Fougerousse F, Beckmann JS, Bushby KM: Dysferlin is a plasma membrane protein and is expressed early in human development. Hum Mol Genet 1999, 8:855-861
5. Kerr JP, Ziman AP, Mueller AL, Muriel JM, Kleinhans-Welte E, Gumerson JD, Vogel SS, Ward CW, Roche JA, Bloch RJ: Dysferlin stabilizes stress-induced $\mathrm{Ca} 2+$ signaling in the transverse tubule membrane. Proc Natl Acad Sci U S A 2013, 110:20831-20836

6. McDade JR, Archambeau A, Michele DE: Rapid actin-cytoskeletondependent recruitment of plasma membrane-derived dysferlin at wounds is critical for muscle membrane repair. FASEB J 2014, 28 : 3660-3670

7. Bansal D, Miyake K, Vogel SS, Groh S, Chen CC, Williamson R, McNeil PL, Campbell KP: Defective membrane repair in dysferlindeficient muscular dystrophy. Nature 2003, 423:168-172

8. Han R, Campbell KP: Dysferlin and muscle membrane repair. Curr Opin Cell Biol 2007, 19:409-416

9. Gallardo E, Rojas-Garcia R, de Luna N, Pou A, Brown RH Jr, Illa I: Inflammation in dysferlin myopathy: immunohistochemical characterization of 13 patients. Neurology 2001, 57:2136-2138

10. Roche JA, Tulapurkar ME, Mueller AL, van Rooijen N, Hasday JD, Lovering RM, Bloch RJ: Myofiber damage precedes macrophage infiltration after in vivo injury in dysferlin-deficient $\mathrm{a} / \mathrm{j}$ mouse skeletal muscle. Am J Pathol 2015, 185:1686-1698

11. Angelini C, Grisold W, Nigro V: Diagnosis by protein analysis of dysferlinopathy in two patients mistaken as polymyositis. Acta Myol 2011, 30:185-187

12. Nguyen K, Bassez G, Krahn M, Bernard R, Laforet P, Labelle V, Urtizberea JA, Figarella-Branger D, Romero N, Attarian S, Leturcq F, Pouget J, Levy N, Eymard B: Phenotypic study in 40 patients with dysferlin gene mutations: high frequency of atypical phenotypes. Arch Neurol 2007, 64:1176-1182

13. Nakagawa M, Matsuzaki T, Suehara M, Kanzato N, Takashima H, Higuchi I, Matsumura T, Goto K, Arahata K, Osame M: Phenotypic variation in a large Japanese family with Miyoshi myopathy with nonsense mutation in exon 19 of dysferlin gene. J Neurol Sci 2001, 184:15-19

14. Vilchez JJ, Gallano P, Gallardo E, Lasa A, Rojas-Garcia R, Freixas A, De Luna N, Calafell F, Sevilla T, Mayordomo F, Baiget M, Illa I: Identification of a novel founder mutation in the DYSF gene causing clinical variability in the Spanish population. Arch Neurol 2005, 62:1256-1259

15. Swaggart KA, Demonbreun AR, Vo AH, Swanson KE, Kim EY, Fahrenbach JP, Holley-Cuthrell J, Eskin A, Chen Z, Squire K, Heydemann A, Palmer AA, Nelson SF, McNally EM: Annexin A6 modifies muscular dystrophy by mediating sarcolemmal repair. Proc Natl Acad Sci U S A 2014, 111:6004-6009

16. Roostalu U, Strahle U: In vivo imaging of molecular interactions at damaged sarcolemma. Dev Cell 2012, 22:515-529

17. Hack AA, Ly CT, Jiang F, Clendenin CJ, Sigrist KS, Wollmann RL, McNally EM: Gamma-sarcoglycan deficiency leads to muscle membrane defects and apoptosis independent of dystrophin. J Cell Biol 1998, 142:1279-1287

18. Cooper ST, Head SI: Membrane Injury and Repair in the Muscular Dystrophies. Neuroscientist 2015, 21:653-668

19. Hayes MJ, Rescher U, Gerke V, Moss SE: Annexin-actin interactions. Traffic 2004, 5:571-576

20. Gerke V, Moss SE: Annexins: from structure to function. Physiol Rev 2002, 82:331-371

21. Lennon NJ, Kho A, Bacskai BJ, Perlmutter SL, Hyman BT, Brown RH Jr: Dysferlin interacts with annexins A1 and A2 and mediates sarcolemmal wound-healing. J Biol Chem 2003, 278:50466-50473

22. Babiychuk EB, Monastyrskaya K, Burkhard FC, Wray S, Draeger A: Modulating signaling events in smooth muscle: cleavage of annexin 2 abolishes its binding to lipid rafts. FASEB J 2002, 16:1177-1184

23. Pederzoli-Ribeil M, Maione F, Cooper D, Al-Kashi A, Dalli J, Perretti M, D'Acquisto F: Design and characterization of a cleavageresistant Annexin A1 mutant to control inflammation in the microvasculature. Blood 2010, 116:4288-4296

24. Damazo AS, Yona S, D’Acquisto F, Flower RJ, Oliani SM, Perretti M: Critical protective role for annexin 1 gene expression in 
the endotoxemic murine microcirculation. Am J Pathol 2005, 166: 1607-1617

25. Smith PD, Davies A, Crumpton MJ, Moss SE: Structure of the human annexin VI gene. Proc Natl Acad Sci U S A 1994, 91:2713-2717

26. Smith PD, Moss SE: Structural evolution of the annexin supergene family. Trends Genet 1994, 10:241-246

27. Buzhynskyy N, Golczak M, Lai-Kee-Him J, Lambert O, Tessier B, Gounou C, Berat R, Simon A, Granier T, Chevalier JM, Mazeres S, Bandorowicz-Pikula J, Pikula S, Brisson AR: Annexin-A6 presents two modes of association with phospholipid membranes. A combined QCM-D, AFM and cryo-TEM study. J Struct Biol 2009, 168: 107-116

28. Demonbreun AR, Fahrenbach JP, Deveaux K, Earley JU, Pytel P, McNally EM: Impaired muscle growth and response to insulin-like growth factor 1 in dysferlin-mediated muscular dystrophy. Hum Mol Genet 2011, 20:779-789

29. Lostal W, Bartoli M, Roudaut C, Bourg N, Krahn M, Pryadkina M, Borel P, Suel L, Roche JA, Stockholm D, Bloch RJ, Levy N, Bashir R, Richard I: Lack of correlation between outcomes of membrane repair assay and correction of dystrophic changes in experimental therapeutic strategy in dysferlinopathy. PLoS One 2012, 7:e38036

30. Hadi AM, Mouchaers KT, Schalij I, Grunberg K, Meijer GA, VonkNoordegraaf A, van der Laarse WJ, Belien JA: Rapid quantification of myocardial fibrosis: a new macro-based automated analysis. Cell Oncol (Dordr) 2011, 34:343-354

31. Straub V, Rafael JA, Chamberlain JS, Campbell KP: Animal models for muscular dystrophy show different patterns of sarcolemmal disruption. J Cell Biol 1997, 139:375-385

32. Pfaffl MW: A new mathematical model for relative quantification in real-time RT-PCR. Nucleic Acids Res 2001, 29:e45

33. Demonbreun AR, McNally EM: DNA Electroporation, Isolation and Imaging of Myofibers. J Vis Exp 2015, 106:e53551

34. DiFranco M, Quinonez M, Capote J, Vergara J: DNA transfection of mammalian skeletal muscles using in vivo electroporation. J Vis Exp 2009, (JoVE)

35. Rayavarapu S, Van der Meulen JH, Gordish-Dressman H, Hoffman EP, Nagaraju K, Knoblach SM: Characterization of dysferlin deficient SJL/J mice to assess preclinical drug efficacy: fasudil exacerbates muscle disease phenotype. PLoS One 2010, 5:e12981

36. Ho M, Post CM, Donahue LR, Lidov HG, Bronson RT, Goolsby H, Watkins SC, Cox GA, Brown RH Jr: Disruption of muscle membrane and phenotype divergence in two novel mouse models of dysferlin deficiency. Hum Mol Genet 2004, 13:1999-2010

37. Lostal W, Bartoli M, Bourg N, Roudaut C, Bentaib A, Miyake K, Guerchet N, Fougerousse F, McNeil P, Richard I: Efficient recovery of dysferlin deficiency by dual adeno-associated vector-mediated gene transfer. Hum Mol Genet 2010, 19:1897-1907

38. Brancaccio P, Lippi G, Maffulli N: Biochemical markers of muscular damage. Clin Chem Lab Med 2010, 48:757-767

39. Cenacchi G, Fanin M, De Giorgi LB, Angelini C: Ultrastructural changes in dysferlinopathy support defective membrane repair mechanism. J Clin Pathol 2005, 58:190-195

40. Confalonieri P, Oliva L, Andreetta F, Lorenzoni R, Dassi P, Mariani E, Morandi L, Mora M, Cornelio F, Mantegazza R: Muscle inflammation and MHC class I up-regulation in muscular dystrophy with lack of dysferlin: an immunopathological study. J Neuroimmunol 2003, 142:130-136

41. McNally EM, Ly CT, Rosenmann H, Mitrani Rosenbaum S, Jiang W, Anderson LV, Soffer D, Argov Z: Splicing mutation in dysferlin produces limb-girdle muscular dystrophy with inflammation. Am J Med Genet 2000, 91:305-312

42. Nagaraju K, Rawat R, Veszelovszky E, Thapliyal R, Kesari A, Sparks S, Raben N, Plotz P, Hoffman EP: Dysferlin deficiency enhances monocyte phagocytosis: a model for the inflammatory onset of limb-girdle muscular dystrophy 2B. Am J Pathol 2008, 172:774-785

43. Mann CJ, Perdiguero E, Kharraz Y, Aguilar S, Pessina P, Serrano AL, Munoz-Canoves P: Aberrant repair and fibrosis development in skeletal muscle. Skelet Muscle 2011, 1:21

44. Heydemann A, Ceco E, Lim JE, Hadhazy M, Ryder P, Moran JL, Beier DR, Palmer AA, McNally EM: Latent TGF-beta-binding protein 4 modifies muscular dystrophy in mice. J Clin Invest 2009, 119: 3703-3712

45. Flanigan KM, Ceco E, Lamar KM, Kaminoh Y, Dunn DM, Mendell JR, King WM, Pestronk A, Florence JM, Mathews KD, Finkel RS, Swoboda KJ, Gappmaier E, Howard MT, Day JW, McDonald C, McNally EM, Weiss RB; United Dystrophinopathy Project: LTBP4 genotype predicts age of ambulatory loss in Duchenne muscular dystrophy. Ann Neurol 2013, 73:481-488

46. Wenzel K, Zabojszcza J, Carl M, Taubert S, Lass A, Harris CL, Ho M, Schulz H, Hummel O, Hubner N, Osterziel KJ, Spuler S: Increased susceptibility to complement attack due to down-regulation of decay-accelerating factor/CD55 in dysferlin-deficient muscular dystrophy. J Immunol 2005, 175:6219-6225

47. Ayoglu B, Chaouch A, Lochmuller H, Politano L, Bertini E, Spitali P, Hiller M, Niks EH, Gualandi F, Ponten F, Bushby K, Aartsma-Rus A, Schwartz E, Le Priol Y, Straub V, Uhlen M, Cirak S, t Hoen PA, Muntoni F, Ferlini A, Schwenk JM, Nilsson P, Al-Khalili Szigyarto C: Affinity proteomics within rare diseases: a BIO-NMD study for blood biomarkers of muscular dystrophies. EMBO Mol Med 2014, 6:918-936

48. Rouillon J, Zocevic A, Leger T, Garcia C, Camadro JM, Udd B, Wong B, Servais L, Voit T, Svinartchouk F: Proteomics profiling of urine reveals specific titin fragments as biomarkers of Duchenne muscular dystrophy. Neuromuscul Disord 2014, 24:563-573

49. Zaks WJ, Creutz CE: $\mathrm{Ca}(2+)$-dependent annexin self-association on membrane surfaces. Biochemistry 1991, 30:9607-9615

50. Mariano A, Henning A, Han R: Dysferlin-deficient muscular dystrophy and innate immune activation. FEBS J 2013, 280:4165-4176

51. Wallner BP, Mattaliano RJ, Hession C, Cate RL, Tizard R, Sinclair LK, Foeller C, Chow EP, Browing JL, Ramachandran KL, Pepinsky RB: Cloning and expression of human lipocortin, a phospholipase A2 inhibitor with potential anti-inflammatory activity. Nature 1986, 320:77-81

52. Christmas P, Callaway J, Fallon J, Jones J, Haigler HT: Selective secretion of annexin 1 , a protein without a signal sequence, by the human prostate gland. J Biol Chem 1991, 266:2499-2507

53. Deora AB, Kreitzer G, Jacovina AT, Hajjar KA: An annexin 2 phosphorylation switch mediates p11-dependent translocation of annexin 2 to the cell surface. J Biol Chem 2004, 279:43411-43418

54. Kamal A, Ying Y, Anderson RG: Annexin VI-mediated loss of spectrin during coated pit budding is coupled to delivery of LDL to lysosomes. J Cell Biol 1998, 142:937-947 